\title{
Bento Quirino e Cotuca: os passos do ensino profissional em Campinas*
}

\section{Bento Quirino and Cotuca: the steps of technical education in Campinas}

\begin{abstract}
Lúcia Pedroso da Cruz
Mestre em Educação, doutoranda pela Faculdade de Educação (Unicamp) e bolsista Fapesp Ipedcruz@yahoo.com.br
\end{abstract}

\section{Resumo:}

Este trabalho apresenta uma (re)construção histórica de duas instituições de Ensino Profissional do município de Campinas, São Paulo. Ambas ocuparam, em tempos diferentes, um edifício especialmente construído para o funcionamento de uma escola de formação profissional, no início do século XX. O Instituto Profissional Bento Quirino ali funcionou de 1915 a 1965 . O Colégio Técnico da Unicamp (Cotuca) iniciou suas atividades em 1967, teve sua instalação oficializada em 1970 e ainda permanece no local. Portanto, o estudo delimitou um recorte temporal de 1915 a 1970.

Palavras-chave: História de instituiçóes Escolares; História do ensino profissional; Políticas públicas

\section{Abstract:}

This paper presents a historical (re)construction of two Professional Teaching Institutions in the municipal district of Campinas, in São Paulo. Both of them occupied, at different periods, one place especially built for the functioning of a professional education school, in the beginning of the 20th century. Bento Quirino Professional Institute functioned there from 1915 to 1965 . The Unicamp Technical School (Cotuca) begun its activities in 1967. In 1970, this school installation became official and it has remained at the place since then. This study was delimited in a period of time between 1915 and 1970.

Keywords: Education institutes; History of technical education; Education politics

* Trabalho apresentado no GT Instituições Escolares na Cidade: Memórias 


\section{Artigos \& Ensaios}

1 - Este trabalho é um recorte de minha Dissertação de Mestrado, orientada pela Profa Dra. Maria Helena Salgado Bagnato, defendido em 22/02/2008, na Faculdade de Educação da Unicamp, com o apoio da Capes.
O estudo[1] a que me propunha ao ingressar no Mestrado na Faculdade de Educação da Unicamp buscava compreender de que maneira(s) professores que lecionavam em cursos técnicos de Enfermagem se apropriavam das políticas educacionais trazidas pela Lei de Diretrizes e Bases da Educação Nacional no . 9394/96 eas contextualizam em sua atividade pedagógica. Escolhi o Colégio Técnico da Universidade Estadual de Campinas (Cotuca), instituição pública que possui entre os vários cursos de formação profissional de nível médio, o de Enfermagem.

Buscando elementos para situar meu objeto de pesquisa, consultei no Siarq (Sistema Central de Arquivos) da Unicamp, alguns documentos, como cartas e memorandos. Estes, somados a um breve histórico encontrado na página do colégio técnico na Internet, levaram-me à informação de que o edifício onde está o Cotuca foi construído no início do século XX, para abrigar o Instituto Profissional Bento Quirino.

$\mathrm{Na}$ etapa seguinte, a pesquisa no CMU (Centro de Memória da Unicamp) indicou, entre outros documentos, o Inventário de Fontes Documentais. Por ele, eu soube que o antigo Instituto Profissional, hoje Escola Técnica Estadual Bento Quirino, contava com um Centro de Memória.

Em visita ao local, encontrei o Livro de Atas com registros das reunióes da Associação mantenedora do Instituto Profissional, além de outros documentos das primeiras décadas de funcionamento da escola, assim como um número especial da Revista de Ciências, Letras e Artes de Campinas, homenageando Bento Quirino.

Diante do material encontrado, optei por alterar o objeto de estudo escolhido inicialmente e aprofundar a pesquisa no percurso histórico da instituição escolar criada no primeiro quarto do século XX.

\section{Bento Quirino dos Santos - o mentor do Instituto Profissional}

Nascido em Campinas, em 18 de abril de 1837, Bento Quirino foi um comerciante próspero e muito ativo na vida política e social da cidade.

Uma edição da Revista de Ciências, Letras e Artes, lançada em 18 de dezembro de 1938 e especialmente dedicada à "memória do saudoso Campineiro Snr. Bento Quirino dos Santos”, por ocasião do seu centenário, reuniu textos e discursos proferidos por diversas pessoas. $\mathrm{O}$ exemplar ainda inclui o texto original do seu testamento, apresentado sob o título de "Um testamento notável".

Entre os discursos, que sugerem as relaçóes de afinidade, de ordem política e/ou afetiva, existentes entre o respectivo autor e o homenageado, o de Osmar Simóes Magro, à página 26 do documento, traz informaçóes sobre a criação do Partido Republicano Paulista e a efetiva participação de Bento Quirino nele.

Bento Quirino pertencera ao chamado Partido Liberal avançado e, por ele foi levado à vereança em 1873. Mas nesse ano reuniu-se a Convençáo de Itu, que resolveu adoptar o manifesto do Clube Republicano do Rio de Janeiro, publicado em 3 de dezembro de 1870. Estava creado o Partido Republicano Paulista, ao qual pertenceram os illustres brasileiros Campos Salles e Francisco Glycerio, dois inesquecíveis campineiros. Bento Quirino logo se filiou à nova agremiação e em suas fileiras militou até os ultimos anos de sua longa vida. 
Logo após o falecimento de Bento Quirino, ocorrido em 26 de dezembro de 1914, foi organizada uma associação integrada por cafeicultores e profissionais liberais - amigos e conhecidos - de modo a administrar da melhor forma o legado de mil contos de réis destinado à criação da escola. A seguir, a transcrição de um trecho do testamento, datado de 1912, em que é especificado o destino a ser dado ao valor deixado por ele: "Deixo para a fundação de um Instituto de ensino profissional masculino em Campinas, isto é, para a construcção de um prédio apropriado e mais elementos de patrimonio, mil contos de réis (...)" (Revista de Ciências e Letras: 41-42).

$\mathrm{Na} 1^{a}$ Ata da Assembleia Geral da "Associação Instituto Profissional Bento Quirino”, realizada em 25 de julho de 1915, o testamenteiro, senhor José Paulino Nogueira, tornou pública a intenção do falecido, lançando a ideia da escola.

O grupo adquiriu uma chácara em um terreno próximo ao renomado colégio Culto à Ciência (Moraes e Alves, 2002), para que ali fosse erguida a nova escola, sendo Francisco de Paula Ramos de Azevedo o responsável pela construção.

A data de 26 de dezembro de 1918 é a que consta das Atas para que uma festa marcasse a inauguração da escola. Porém, nos documentos que compóem o processo de tombamento desta construção, solicitado em 1983, está explicitado o seguinte: "as obras foram iniciadas em abril de 1916, sendo que em ' 02 de abril de 1918', as aulas foram ministradas no novo prédio do Instituto Profissional Bento Quirino, sob a direção do Engenheiro Bruno Simóes. Conforme relatório da Instituição" (CARNEIRO, 1984) [2]. [grifo meu]

Fica o convite à reflexão sobre a forma como essas atividades políticas vieram a público, por meio de registros históricos - cercados de subjetividades, interesses e, portanto, pouca (ou nenhuma) neutralidade. Isto vem ao encontro do conceito de documento de Jacques Le Goff:

O documento não é inócuo. É, antes de mais nada, o resultado de uma montagem, consciente ou inconsciente da história, da época, da sociedade que o produziram, mas também das épocas sucessivas durante as quais continuou a viver, talvez esquecido, durante as quais continuou a ser manipulado, ainda que pelo silêncio. $\mathrm{O}$ documento é uma coisa que fica, que dura, e o testemunho, o ensinamento (para evocar a etimologia) que ele traz devem ser em primeiro lugar analisados, desmistificando-lhe o seu significado aparente. 'O documento é monumento’ [grifo meu] (LE GOFF, 2005: 537-538).

Assim, ao mergulhar nos documentos e encontrar as origens desta história em outro tempo-espaço, vislumbrei a possibilidade de trazer na pesquisa uma trajetória dessas duas escolas ao longo do tempo, buscando contextualizar o momento histórico, à luz das políticas públicas educacionais.

Para Marc Bloch, história é busca, portanto escolha. Seu objeto não é o passado e sim o homem, ou melhor, "os homens", mais precisamente "homens no tempo". Acredita que é essencial ao ofício de historiador "compreender o presente pelo passado" e, de forma correlata, "compreender o passado pelo presente" (BLOCH, 2001).
2 - Maria Luiza Tucci Carneiro é a historiadora que assina o levantamento histórico realizado para compor o dossiê de documentos encaminhados com a finalidade de se justificar a solicitação do Processo de Tombamento do edifício. Este trabalho é datado de 30 de julho de 1984 e está registrado na Fls. 52 do Processo 6 de Tombamento do Colégio Técnico da Unicamp, disponível para consulta no CMU. 
3 - Disponivel em: http:// www.bvsalutz.coc.fiocruz. $\mathrm{br} / \mathrm{html} / \mathrm{pt} / \mathrm{static/trajeto-}$ ria/volta_brasil/campinas. htm.. Não há especificação de autor. Acesso em 06/06/2007.

\section{A cidade de Campinas no final do século XIX}

O surgimento da cidade de Campinas nos remete ao século XVIII, quando um grupo de desertores de uma bandeira vindo da Vila de Piratininga em 1772 teria originado o primeiro núcleo de moradores. Com pequena populaçáo e agricultura de subsistência, ficou subordinada a Jundiaí (ANANIAS, 2000 e NASCIMENTO, 1999).

Mais tarde, o crescimento econômico e o cumprimento de requisitos, como: "comprovar a existência de pessoas capacitadas para exercer essas funçóes políticas, administrativas, jurídicas e militares" - garantiram conquistar a categoria de vila, a Vila de São Carlos, entre 1797 e 1842. Com isso, rompia-se a dependência de Jundiaí. Mantendo a economia em ascensão, a Vila não tardou a ser reconhecida como cidade e passou a se chamar Campinas (ANANIAS, 2000:14).

O município vinha em um ritmo de desenvolvimento tal que, em vários momentos, fez com que tivesse mais projeçáo que a própria cidade de Sáo Paulo. Entre 1870 e 1880, foi considerada a Capital Agrícola da Província (SEMEGHINI, 1988 e SOUZA, 1998).

A intensificação do fluxo urbano, com maior giro de capital, estimulou a construção de benfeitorias e foi acompanhada por mudanças, principalmente de ordem cultural. Em meados dos anos de 1880, já havia vários estabelecimentos atacadistas, casas comissárias de café, hotéis e restaurantes, colégios, duas bibliotecas públicas, orquestra e bandas de música, várias sociedades de socorro mútuo, sociedades literário/científicas e sociedades alemãs, italianas, inglesas, francesas, suíças, espanholas, ligadas às respectivas colônias e responsáveis pela manutenção de clubes, escolas e hospitais (HADLER, 2007 e LAPA, 1995).

Porém, no período entre 1889 e 1892 e ainda em 1896 e 1897 (Lapa, 1995), a cidade sofreu reveses, quando epidemias de febre amarela dizimaram boa parte da população, "chegando a quarenta óbitos por dia" [3] provocando o êxodo de pessoas e estabelecimentos comerciais e industriais.

Ainda segundo Lapa (1995), nos anos 90 do século XIX, os serviços de higiene e sanitários passam a ser centralizados pelo Estado, a partir da Lei No 432 de 3 de agosto de 1896 e do Regimento de 7 de outubro do mesmo ano.

Diversas medidas foram adotadas para o "melhoramento, expansão, imagem e estética", da cidade: retificação de córregos, drenagem de pântanos e charcos, instalação de canos de água e esgotos, calçamento e arborização de ruas. "A moralização das ruas, a normatização dos comportamentos públicos" fazem aflorar "uma preocupação com a higiene pública, com a limpeza das ruas, atendendo aos anseios de constituiçáo de uma cidade civilizada e de progresso" (HADLER, 2007: 49).

Lapa (1995) comenta a respeito das tensôes políticas envolvidas em todo esse conjunto de melhorias do espaço urbano de Campinas:

De certa maneira, essas intervençôes cirúrgicas corretivas que sofreu Campinas com o projeto do engenheiro sanitarista Saturnino de Brito, guardadas as especificidades da cidade, os estragos causados pela febre amarela e os esforços para debelar e prevenir a epidemia estão inseridos num quadro mais amplo, em termos nacionais, que o regime republicano empreende, alterando as formas urbanas herdadas do Império (LAPA, 1995: 262). 


\section{As PRIMEIRAS ESCOLAS DE CAMPINAS}

O setor educacional também foi palco de disputas, envolvendo relaçóes de poder e embates centrados em vantagens políticas de um grupo hegemônico. "É importante ter em conta que, a classe dominante expressa uma identidade de interesses - ela fala em nome de todos - tendo como modelo os seus próprios interesses" (WARDE, 1977: 49).

Segundo SOUZA (1998: 117), as elites políticas campineiras “... orgulhavam-se do fato da cidade ter sido o berço do movimento republicano" e trataram de fazer do Partido Republicano Paulista - PRP - o reflexo de seus interesses, reproduzindo, no entanto, por um bom tempo, distorçôes de um regime oligárquico: “... votos de cabresto, fraudes eleitorais, a influência dos coronéis, herdeiros muito próximos da vanguarda dos fazendeiros do Oeste Paulista...”.

Em contraste com a efervescência econômica pela qual a novata cidade de Campinas passava, o setor educacional mostrava pouca pressa para alcançar o mesmo sucesso.

A primeira lei referente à Instrução Pública Nacional do Império do Brasil foi aprovada em 15 de outubro de 1827 e estabelecia que “... em todas as cidades, vilas e lugares populosos haverá escolas de primeiras letras necessárias”. Estabeleceu-se também que ficariam a cargo dos presidentes de cada província os custos com o pagamento de professores e estes, por sua vez, deveriam arcar com as despesas destinadas à sua formação, a ser providenciada em curto prazo. $\mathrm{O}$ conteúdo a ser ensinado incluía fundamentos morais e religiosos da religiáo Católica Apostólica Romana e ensino de leitura baseado em temas sobre História do Brasil e Constituição do Império (NASCIMENTO, s/d).

Porém, tais deliberaçóes conduziram a resultados incipientes quanto à implantação e ao funcionamento de escolas. Nascimento (op.cit.) observa que o governo lançou um discurso ideológico em que se dizia preocupado com a instrução popular, mas não levou em conta as reais condições do país e foi omisso no provimento de recursos para possibilitar o desenvolvimento da educaçáo.

No cenário educacional do final do Império, o quadro geral do Brasil apresentava, segundo Maria Isabel Moura Nascimento, “poucas Instituições Escolares, com apenas alguns liceus nas capitais, colégios privados bem instalados nas principais cidades, cursos normais em quantidades insatisfatórias no país". A autora completa referindo-se ao "grande abismo educacional entre a maioria da população brasileira, que, quando muito, tinha uma casa e uma escola, com uma professora leiga para ensinar os pobres brasileiros excluídos do interesse do governo Imperial" (NASCIMENTO, s/d).

Sobre o modo de os republicanos paulistas entenderem a questão do ensino básico, Beisiegel diz: "enquanto no Estado de São Paulo a legislação consagrava o ensino obrigatório para todas as crianças em idade escolar, no âmbito federal prevaleciam as teses de descentralização do ensino e postergava-se a consolidação legal da obrigatoriedade para bem mais tarde" (BEISIEGEL, 1974b: 56 apud MORAES, 2006: 150).

E assim, Campinas também enfrentava uma situação escolar bem defasada quanto às necessidades e demandas da população.

As figuras relevantes no cenário político e econômico da cidade aparecem, igualmente, envolvidas no cenário educacional. Embora não caiba menosprezar o sincero interesse de algumas pessoas pelo desenvolvimento da qualidade do ensino, também não se pode deixar de problematizar o vínculo entre interesses 
políticos, econômicos e sociais e a influência que tal relação exerce na construção de políticas públicas, inclusive as educacionais.

O que não consta nas crônicas da época e se omite em estudos posteriores é que, além de fazendeiros dedicados ao plantio e à comercialização de café, além de industriais, comerciantes ou bacharéis, além de republicanos - e, talvez, por causa disso mesmo -, eram os idealizadores, organizadores e diretores da Sociedade Culto à Ciência, bem como todo o seu corpo docente, membros da Maçonaria (MORAES, 2006: 124).

Tendo como base uma ideologia liberal e o positivismo, representados pela "autonomia da razão contra a autoridade religiosa", pela "autonomia do indivíduo diante do Estado", a Loja [Maçônica] Independência de Campinas funda na cidade a primeira instituição de ensino de caráter totalmente leigo (MORAES, 2006).

Isso coincide com um discurso em defesa da educação, que associa a escolarização à garantia de desenvolvimento social e a ignorância como sendo o grande obstáculo para a marcha do progresso.

O povo que tem as melhores escholas é o primeiro povo; se elle não o é hoje, sel-o-há amanhã. Nem um outro progresso é realmente possível sem a cooperação do ensino, esse elemento primordial da civilisação, tal como a entende a sociedade destes tempos (Almanak de Campinas para 1871. Campinas, SP: Typ. da Gazeta de Campinas, 1870:75 apud ANANIAS, 2000: 31).

Souza (1998), ao discutir questóes relativas à instrução popular em Campinas, alerta para o fato de náo ser esta uma proposta originalmente republicana. Nos períodos Colonial e Imperial já apareciam deliberaçôes a respeito. A inovaçáo republicana consistiu na "articulação orgânica pelas classes dominantes de um ideário liberal democrático, em torno da educação popular e a determinação empreendida a fim de implantar, efetivamente, um sistema de ensino popular no país, consoante a nova ordem social" (SOUZA, 1998: 26).

No decorrer do período Imperial e nos primeiros anos da República aparecem poucas alusôes específicas a escolas de ensino profissional e à existência de uma legislação sistematizada.

\section{AS ESCOLAS PROFISSIONALIZANTES}

Em 1826, surgiu pela primeira vez na história da educação nacional um Projeto de Lei sobre a Instrução Pública no Império que pretendia organizar o ensino público no país. Em um primeiro momento, não havia referências ao ensino de ofícios. No ano seguinte, em 1827, o Projeto foi aprovado, determinando que nas escolas profissionalizantes ocorresse a inclusáo e obrigatoriedade das meninas na aprendizagem de costura e bordado, enquanto nos Liceus os meninos aprenderiam o desenho necessário às artes e ofícios (FONSECA, 1961 apud SANTOS, 2003: 209). 
Nota-se que a legislação sobre a Instrução Pública referente à educação das meninas estava desenhada em função do papel social feminino: as prendas domésticas.

Luiz Antonio Cunha apresenta uma análise crítica sobre os contextos social, político e econômico durante o início do século XX, ocasião em que são criadas escolas profissionais nos vários estados brasileiros. Em uma síntese de ideias:

O aumento constante da população das cidades exige que se facilitem às classes proletárias os meios para vencer as dificuldades sempre constantes da luta pela existência [...] para isso se torna necessário, não só habilitar os filhos dos desfavorecidos da fortuna com o indispensável preparo técnico e intelectual, como fazê-los adquirir hábitos de trabalho profícuo, que os afastará 'da ociosidade, escola do vício e do crime' [grifo do autor] (CUNHA, 2000: 94).

A nova ideologia se traduziu em políticas educacionais. Em 1906, na condição de Presidente do Estado do Rio de Janeiro, Nilo Peçanha, em ação inédita, baixa um Decreto criando cinco escolas profissionais: três para ensino manufatureiro e duas para ensino agrícola. Em 1909, como Presidente da República, cria 19 escolas de aprendizes e artífices, uma em cada estado. Tais escolas ficaram sob a responsabilidade do Ministério da Agricultura, Indústria e Comércio até 1930 e eram regidas por legislação exclusiva e metodologia didática própria, além de possuírem prédios e currículos específicos (CUNHA, 2000).

Regulamentadas pelo Decreto 7.566, de 23/9/1909, as escolas tinham os critérios para admissáo de alunos claramente explicitados no seu artigo $6^{\circ}$ : ter a idade de dez anos no mínimo e treze anos no máximo e a preferência na matrícula deveria recair sobre os desfavorecidos da fortuna (CUNHA, 2000 e SANTOS, 2003).

Em São Paulo, as Escolas de Aprendizes Artífices adquiriram características próprias, devido à grande expansão da produção industrial no Estado e da concorrência representada pelo Liceu de Artes e Ofícios. Desde o início de seu funcionamento, já ofereciam curso de tornearia, mecânica e eletricidade e nunca formaram sapateiros ou alfaiates, modalidades comuns em escolas de outros estados.

Neste contexto, em Campinas, o Governo do Estado assumiu "a direção e manutenção das classes e officinas entrando na posse do Instituto [Bento Quirino] e recebendo uma anuidade tirada das rendas do patrimônio". Isto é, o governo assumiu, no ano de 1927, maior controle da escola, mas o acordo garantia que não houvesse rupturas no aspecto financeiro, de modo que a Associação privada continuava repassando valores ao órgão público.

Onze anos depois de apresentados os desígnios de Bento Quirino sobre a criaçáo de uma escola masculina de ensino profissional, a proposta de se abrir espaço para meninas vem sinalizar uma adaptação à demanda da população, anunciando a ampliação das funçóes femininas em uma sociedade que se moderniza.

Considerada a primeira escola técnica mista do Estado, a instituição idealizada por Bento Quirino oferecia cursos técnicos que contavam com aulas de por- 
4 - Inventário de Processos Permanentes, Processo 3176/70 será citado como PR PERM e o número da folha.

5 - Zeferino Vaz já acumulava em sua trajetória acadêmica: a direção de Faculdade de Medicina Veterinária da USP; a criação e direção da Faculdade de Medicina da USP de Ribeirão Preto; a presidência do Conselho Estadual de Educação, além de ter sido reitor-interventor $d a$ UnB. Assumiu a Reitoria em 1966 e permaneceu na função até 1978. tuguês, educação física, aritmética, geometria e desenho industrial e cursos profissionais, como: costura em geral (bordados a máquina, cursos de flores, roupas brancas, chapéus e artes aplicadas), mecânica geral (ferraria, fundição, serralheria, ajustagem, forno e fresza); marcenaria (3 anos, torneado em madeira, entalhes e confecção de móveis e outros artefatos), técnico prático de economia doméstica (noções de culinária, defesa, higiene sanitária e cuidado com as crianças).

A década de 1930 foi momento de grande desenvolvimento do "Bento Quirino". Com os alicerces do governo Vargas (voltada a ideiais como "raça fortalecida', 'povo forte', 'povo produtivo'), as escolas profissionais receberam atenção, pois eram as que preparavam o trabalhador que deveria ser saudável e bem nutrido para melhor produzir. A criação do Dispensário de Puericultura em 1933, nas dependências da escola de Campinas, constituiu um exemplo da implantação das políticas de eugenia que predominavam nas açóes do governo federal.

Ao longo das décadas de 1950 e de 1960 acentuaram-se dificuldades financeiras e foram necessárias reformas na escola profissional. Em 1965, o prédio da Rua Culto à Ciência e seus anexos foram transferidos para o Estado, e em 1966, o espaço projetado e construído por Ramos de Azevedo foi interditado, em função dos sérios problemas estruturais que apresentava.

O Instituto Bento Quirino ocupou o prédio construído na Rua Culto à Ciência, no ${ }^{\circ}$ 177, na região central de Campinas, até 1965. O então Ginásio Industrial foi deslocado para novas instalaçôes em outro endereço no mesmo município e a atual Escola Técnica Estadual Bento Quirino faz parte do Centro de Educação Tecnológica Paula Souza.

\section{A chegada do Cotuca ao prédio da Rua Culto à Ciência}

$\mathrm{Na}$ época em que tiveram início os movimentos pela implantação de um curso superior, a cidade de Campinas - com excelente localização geográfica - já dispunha de um novo sistema rodoviário (a Rodovia Anhanguera havia sido inaugurada em 1948); era servida por uma boa malha ferroviária e já existiam planos para a construçáo do aeroporto de Viracopos desde 1950 (SEMEGHINI, 1998).

Diante deste cenário e com o objetivo de atender a uma crescente demanda de alunos que iam até a capital buscar formação universitária (MENEGHEL, 1994), foi publicada no Diário Oficial de 29 de dezembro de 1962, a "Lei No. 7655, de 28 de dezembro de 1962, [que] dispóe sobre a criação da Universidade de Campinas como entidade autárquica e dá outras providências" (PR PERM, Processo 3176/70, Fls.11) [4].

Uma Comissão Organizadora foi criada com a missão de planejar uma Universidade, que deveria se constituir de várias Faculdades e Institutos. Neste momento, o Professor Zeferino Vaz [5] foi convidado para compor a Comissão e, à frente dela, teve atuação "decisiva para os rumos que a Unicamp iria tomar nos primeiros anos de sua implantação" (MENEGHEL, 1994: 145).

Na opinião dele: "A instalação de uma Instituição de Ensino Superior não depende exclusivamente da questão financeira: o problema material é o capital humano, professores capacitados para o ensino de alto nível, que possuam interesse pelas pesquisas e pelas atividades pedagógicas" (Folha da Manhã, 31/03/53 apud MENEGHEL, 1994).

Entre as diversas finalidades da Universidade de Campinas, explicitadas no artigo $2^{\circ}$ da Lei No. 7655, de 28/12/1962, consta a de 'formar e treinar técnicos de nível médio e superior'. [grifo meu] 
E ainda, segundo o artigo 70: "As 'Escolas Técnicas' dedicar-se-ão à 'formação e treinamento de técnicos de nível médio"” (PR PERM, Fls.12). [grifo meu]

Então, para que fossem organizados quadros docentes, providenciadas as compras de equipamentos específicos e organização de espaço físico para as instalaçóes das demais unidades constituintes da Universidade Estadual de Campinas, foram convidados cientistas altamente conceituados em suas respectivas especialidades. A partir de 1967, formaram o Conselho Diretor da Unicamp (MENEGHEL, 1994).
A Unicamp foi, portanto, organizada em consonância com os princípios que caracterizam a Universidade tec- nocrática (racionalidade, eficiência, produtividade, eco- nomia), devendo ser vista como uma empresa que dá lucro, pois estava voltada para o desenvolvimento indus- trial do país (na formação de máo-de-obra especializa- da, de uma política de ciência e tecnologia), servindo ao modelo de crescimento econômico adotado pelo Estado. [...] a despeito da preocupação da C.O. com a formação humanística dos alunos, não era seu objetivo formar as elites culturais nem os futuros dirigentes da nação; ela pretendia formar um pólo de desenvolvimento tecnoló- gico que suprisse a demanda de indústrias e empresas. Para tanto, iria promover atividades de ensino, de pes- quisa e de extensão. (MENEGHEL, 1994: 148).

Entre os documentos do Inventário de Processos Permanentes, há uma cópia do Diário Oficial, publicado em 28 de janeiro de 1967 (PR PERM, Fls.33), referente à ocupação legal do prédio onde estava o Ginásio Industrial Bento Quirino. Diz o texto: "Êsse prédio foi doado à Fazenda do Estado de São Paulo, pela Associação Instituto Profissional Bento Quirino, para o 'expresso fim' [grifo meu] de ser mantido ali, em funcionamento, uma escola profissional”. E prossegue: "[...] autorizou a Universidade de Campinas a instalar e manter o seu Colégio Técnico, até que pudesse transferi-lo para os prédios a serem construídos na Cidade Universitária”.

Assim, em 1967, foi assinado um convênio entre a Secretaria de Estado dos Negócios da Educação e a Unicamp para funcionamento de seu Colégio Técnico. $\mathrm{Na}$ ocasião também foi instalada, em caráter provisório, a própria Reitoria. Segundo o acordo firmado, enquanto o prédio servisse à Universidade, esta seria responsável por sua administração, o que vem ocorrendo até hoje, 45 anos depois.

Três anos mais tarde, em 1970, formalizou-se o processo de instalação da nova escola.

\section{CONSIDERAÇÓES FINAIS}

Naquela Campinas do final do século XIX e início do século XX, de ares republicanos, havia determinada mobilização "das classes urbanas em torno do alistamento eleitoral e do voto secreto como instrumentos de combate às oligarquias e de consequente republicanização da República” (CARVALHO 2003: 228).

As primeiras escolas de artes e ofícios surgem no país a partir de 1909 e, 


\section{Artigos \& Ensaios}

6 - O professor Omar Salles de Figueiredo foi o $2^{\circ}$ diretor do Colégio Técnico da Unicamp (Cotuca), de 1970 a 1974 e concedeu entrevista para o trabalho da dissertação. nas palavras de KUENZER (2007: 27), o surgimento da formação profissional como política pública no Brasil ocorreu sob a "perspectiva moralizadora da formação do caráter pelo trabalho".

Nestas circunstâncias, em 1915, anunciou-se o conteúdo do testamento de Bento Quirino dos Santos, determinando a construção de uma escola, que deveria oferecer ensino profissional para meninos pobres, reafirmando o ideário republicano da educação.

KUENZER (2007) assinala que a dualidade histórica dos sistemas de ensino propedêutico e profissional é mantida pela reforma Capanema de 1942. Em seguida, as Leis Orgânicas do Ensino Profissional conseguiram atenuar um pouco essa dicotomia, permitindo que os egressos de escolas profissionalizantes tivessem acesso a cursos superiores, fizessem provas de adaptação a respeito de disciplinas do propedêutico.

A mesma autora também explica que o reconhecimento de outros saberes na formação de um jovem, manifestado pela LDB de 1961, foi resultado do intenso crescimento nos setores secundário e terciário do país. Por outro lado, continuam a existir os dois ramos de ensino e, na prática, o dualismo mantém-se.

[O Ensino Profissional] era para sujar as mãos e o outro era para colarinho branco. A Constituição de 46 estabeleceu em um de seus itens, essa possibilidade do ensino prático-teórico, teórico-prático. Mas a Lei ficou 15 anos no Senado e só foi aprovada em 1961 - que é a Lei de Diretrizes e Bases da Educação. Foi aí que se instituiu o Ensino Industrial como elemento ao lado do ensino de Letras e Humanidades, que era a tradição brasileira (Prof. Osmar de Figueiredo [6].

Depois de permanecer fechado por cerca de um ano e passar por reformas, aquele edifício no centro de Campinas foi reaberto em 1967, para abrigar novamente uma escola para a formação de técnicos. O Colégio Técnico da Unicamp chegava sob uma perspectiva bem diferente daquela do início do século: não mais para meninos desfavorecidos e, sim, para uma populaçáo de jovens que procurava ensino de qualidade e tinha na grande empresa uma das possibilidades de trabalho.

Sáo as duas instituiçôes a marcar presença na antiga chácara da Rua Culto à Ciência no 177 , sendo que o Cotuca ali permanece, abrigando vidas, desejos, sonhos e possibilidades — construindo história(s), enfim. E como ensina Marc Bloch (2001:55), a "História é a ciência dos homens, no tempo. [...] esse tempo é por natureza, um continuum. É também perpétua mudança”.

\section{FONTES}

BRASIL, Ministério da Educação. Secretaria de Educação Média e Tecnológica. Referenciais Curriculares Nacionais da Educação Profissional de Nivel Técnico. Brasília: MEC, 2000.

BRASIL, Ministério da Educação. Secretaria de Educação Média e Tecnológica. Unidade de Coordenação de Programas. Programa da Expansão da Educação Profissional. Educação Profissional-Legislação Básica. Brasília: MEC, 2001.

Centro Estadual de Educação Tecnológica Paula Souza (CEETEPS). Livro de 
Atas 1915 - 1973. Centro de Memória. Campinas. ETE Bento Quirino.

Centro Estadual de Educação Tecnológica Paula Souza (CEETEPS). Revista de Ciências, Letras e Artes de Campinas. 18 de dezembro de 1938. Centro de Memória. Campinas. ETE BENTO QUIRINO.

Centro Estadual de Educação Tecnológica Paula Souza (CEETEPS). Livro de Atas 1915 - 1973. Centro de Memória. Campinas. ETE Bento Quirino

Universidade Estadual de Campinas (Unicamp). Processo 3176/70: Documentação prevista na Resolução 16/64 do CEE para instalação do Colégio Técnico de Campinas. Campinas, 1969. Arquivo Central do Sistema de Arquivos da Unicamp.

\section{REFERÊNCIAS BIBLIOGRÁFICAS}

ANANIAS, Mauricéia. "As escolas para o povo em Campinas: 1860-1889. Origens, ideário e contexto”. Dissertação de Mestrado. Campinas; Unicamp, 2000.

BLOCH, Marc. Ofício de Historiador (ou Apologia da História). Rio de Janeiro: Jorge Zahar, 2001.

CARVALHO, Marta Maria Chagas de. "Reformas da instrução pública”. In: LOPES, Eliane M. Teixeira; FARIA FILHO, Luciano Mendes; VEIGA, Cynthia Greive (orgs.). 500 Anos de Educação no Brasil. Belo Horizonte, MG, 2003.

CUNHA, Luiz Antonio. "O ensino industrial-manufatureiro no Brasil”. Revista Brasileira de Educação, maio-agosto, n. 014 p. 89-107, 2000. Disponível em: http://redalyc.uaemex.mx/redalyc/pdf/275/27501406.pdf. Acesso em 30/08/2007.

HADLER, Maria Sílvia Duarte. “Trilhos da modernidade: memórias e educação urbana dos sentidos". Tese de Doutorado. Campinas: Unicamp, 2007.

KUENZER, Acácia. Ensino Médio: Construindo uma Proposta Para os que Vivem do Trabalho. São Paulo: Cortez, 2007.

LAPA, José Roberto Amaral. A Cidade: Os Cantos e os Antros - Campinas 18501900. São Paulo: Edusp, 1995.

LE GOFF, Jacques. História e Memória. Campinas: Unicamp, 2005.

MENEGHEL, Stela Maria. "Zeferino Vaz e a Unicamp: uma trajetória e um Modelo de Universidade”. Dissertação de Mestrado. Faculdade de Educação. Unicamp. Campinas, 1994.

MORAES, Carmen Sylvia Vidigal. O Ideário Republicano e a Educação. Campinas: Mercado das Letras, 2006.

MORAES, Carmen Sylvia Vidigal; ALVES, Júlia Falivene (org.). Contribuição para a Pesquisa do Ensino Técnico em São Paulo: Inventário de Fontes Documentais. São Paulo: Centro Paula Souza, 2002.

NASCIMENTO, Maria Isabel Moura. "O Império e as primeiras tentativas de organização da educação nacional (1822-1889)”. [s/d]. Disponível em: <http://www.histedbr.fae.unicamp.br/navegando/periodo_imperial_intro. html> Acesso em 06/6/2007.

NASCIMENTO, Terezinha Aparecida Quaiotti Ribeiro do et al. Memórias da Educação: Campinas (1850-1960). Campinas: Editora da Unicamp, Centro de Memória Unicamp, 1999.

SANTOS, Jailson Alves dos. "A trajetória da educação profissional”. In: LOPES, 
Eliane M. Teixeira; FARIA FILHO, Luciano Mendes; VEIGA, Cynthia Greive (orgs.). 500 Anos de Educação no Brasil. Belo Horizonte, MG, 2003.

SEMEGHINI, Ulysses C. "Campinas (1860-1980): agricultura, industrialização e urbanização". Dissertação de Mestrado. Instituto de Economia. Campinas, Unicamp, 1988.

SOUZA, Rosa de Fátima. O Direito à Educação: Lutas Populares pela Escola em Campinas. Campinas: Área de Publicaçôes CMU/UNICAMP, 1998.

WARDE, Mirian Jorge. Educação e Estrutura Social: A Profissionalização em Questâo. Sáo Paulo: Cortez \& Moraes, 1977. 